\title{
The Study on the Development Process of Urbanization and Strategy Choice in China
}

\author{
Lv Jian ${ }^{1}$ \\ ${ }^{1}$ North China Institute of Aerospace Engineering
}

\begin{abstract}
Urbanization has left deep imprint on social-economic construction, but at the same time raises many problems for policy makers. So this article analyzes the situation of urbanization in megacities, medium-sized and small cities in different periods based on the current situation, and proposes several development strategy choices for the development of urbanization in China.
\end{abstract}

Keywords: Urbanization in China; problems; strategy choice;

\section{INTRODUCTION}

\section{The Current Distinctive Features of China's Urbanization}

China's large-scale urbanization over the past three decades has been unprecedented in human history. Nearly half a billion people have moved into cities, adding to a total of 700 million urban residents. In 1949, only around 11 percent of Chinese lived in cities. By the end of 2012, the proportion of China's urban population had exceeded 52.57 percent. $^{[1]}$

\subsection{Megacities and its characteristics of urbanization}

\subsubsection{Overview of Urbanization Development}

By the end of 2011, the number of megalopolis in China has reached 66, bit cities nearly 100. But the shortage of resources and the environment of the growing tension drove us to seek a new development mode. Now, it is to improve decision-making that China strengthens the building of city group which rally around the development of large cities. The construction of megalopolis and urban agglomeration has become the main goal of the regional economic and social development.

\subsubsection{Characteristics of Urbanization}

First, uneven distribution of space and remarkable regional differences in urban development

In China, the scale of urbanization depends on where people live. In general, the level is higher in the east and north-east, and lower in the central and west. The movement to urban areas is currently accelerating faster in the eastern and central regions, however, and slower in the north-east. We analyze and find that most of megacities concentrated in eastern China and central south region, which accounted for 54 percent of the total. In China's six major districts, about 55 percent of megalopolis is grouped in the southeast coastal district, the northeast region and western region each have 9 megalopolis. The spatial distribution patterns of megacities are not uniform and the regional difference is obvious.

Second, the cluster development of urbanization and high production efficiency

At present, China have formed ten big urban agglomeration: Beijing-Tianjin-Hebei, Yangtze River Delta, Pearl River Delta, Shandong Peninsula, South Central Liaoning, the Central Plains, the middle reaches of the Yangtze River, the west side of the Straits, Sichuan and Chongqing, and Guanzhong urban agglomeration. These megacities revolve around the provincial capital city and promote the joint development of other cities. At large against the backdrop of growing economic globalization, worldwide resources, capital, labor and other elements gather and exchange in these three urban agglomerations, and regional consciousness among regions have been increased, which ceaselessly deepen interdependence and interpenetration among regions. So, these urban agglomerations have become a national leader in national economic development.

Third, the high agglomeration of resources, and obvious development advantage

Megacities mostly are regional central cities, which most manufacturing and service production is more efficient when undertaken in these areas where companies can more conveniently copy best practice in technology and management from more advanced companies, and more easily access skilled workers as well as transport services and other intermediate inputs. Moreover, due to megacities are mostly political and economic center, so all aspects megacities have obviously advantages.

Fourth, the urban population overload and resources and environment problems seriously

From 2000 to 2010, the total population growth in top 20 cities with the highest population growth rate in China reached as high as 38.88 million, accounting for 45.3 percent of the total growth of population in all prefecture level cities. Rapid urbanization has come at high cost to the environment and the resources upon which human development depends. The concentration of industries in urban areas has led to pockets of severe urban pollution, fouling air and water. 


\subsection{Small and medium-sized cities and its characteristics of urbanization}

\subsubsection{Develop Profiles}

By the end of 2012, all regions influenced by small and medium-sized cities directly or indirectly have reached 881 million square kilometers, accounting for 91.7 percent of China; the population reached 1.018 billion, accounting for 75.2 percent of total population. In 2012, economic gross amounts to 29.52 trillion yuan, accounting for 56.8 percent of the total national economy. The healthy development of small and medium-sized cities is of decisive significance for realizing integration urban and rural area, improving the demand structure, building a moderately prosperous society and speeding up socialist modernization.

\subsubsection{Develop Profiles}

First, the level of development is uneven, significant regional differences

Task group of scientific evaluation system for the development of small and medium-sized cities in 2014 research suggests that the top 10 cities all located in the eastern region. Among national comprehensive strength hundred counties (cities), the eastern region holds 59, central, western and northeast regions occupied 16, 13 and 12 respectively.

Second, the spatial distribution of general equilibrium, and the overall development of relatively stable

In each province, autonomous region, small and medium-sized cities play very important roles and its distribution is relatively uniform. From 2004 to 2012, although the number of small and medium-sized cities decreased somehow, the average population size of small and medium-sized cities increased from 542.83 million to 711.82 million, the proportion of urban residents in small and medium-sized cities increased from 41.46 percent to 52.57 percent. From the overall point of view, the development of small and medium-sized cities in China is relatively stable, non-agriculture population keeps increasing steadily.

Third, the extensive mode of economic development, the poor quality of urbanization

China's urban system operates in a strict administrative hierarchy. Due to lack of market competition, concept of sustainable development, system innovation and technical innovation are relatively backward in these cities. Rapid economic development and rise relies on high input, high consumption of energy resources, even spoiling ecological environment. In some key basins and coastal areas, for instance, water pollution is so severe, as is the phenomenon of cloudy brownish haze in some regions and cities, and the emission of major pollutants exceeds the environmental capacity in many regions.

\section{Policy options for the healthy development of small and medium-sized cities urbanization}

The region diffidence of

urbanization development is remarkable, and

always expanding, different of cities and different development stage have its own distinct characteristics and different demands, so that urbanization should take diversified way to suit local conditions and put forward the healthy sustainable urbanization strategy to suit their individual need, which is the key of urbanization.

\subsection{Rational control of megalopolis and large cities, promote the qualities of city life}

2.1.1. Control the city sprawls, improve efficient land use In some big city development, the phenomenon of onesided pursuit of city economic growth and city sprawls appeared, while ignore the bearing capacity of the city. Urbanization has largely developed on land conversion and land financing, which is causing inefficient urban sprawl and, on occasion, ghost towns and a lot of people have become because the "ant tribe" or "mouse tribe" because of rising home prices. So in the development of megalopolis and large cities in the future, we should pay attention to improve the efficiency of land use, optimize the structure of land use, innovate upon land management system and meet the demand of urbanization land use reasonably.

2.1.2. Improve urban function, promote urban diversification

We should vigorously transform traditional industries, try to

develop tertiary industries, particularly modern service industries. There should be vigorously improved urban infrastructure with the IT industry, financial industry and other advanced industries. Construct urban innovation network based on close cooperation with universities, scientific research and education departments, to safeguard function of continuous innovation in large cities; Expand ceaselessly opening to the outside and promote extensive economic and technological exchanges and cooperation with other countries and regions to increase the economic efficiency.

2.1.3. Strengthen the construction of ecological environment, building green and ecologic city

Building a green ecological city is the most main is to change the pattern of economic development in big cities, accelerate the construction of high and new technology industry, advocates the concept of energy conservation and emission reduction. Guide urbanization and coordinated development of urban and rural areas in an orderly manner, optimizing the allocation of urban and rural spatial resources and control of development scale, protecting the regional ecological environment and integrated use of resources. Guide the reasonable urban population growth, advocate green low carbon lifestyle to integrate low-carbon targets with ecological concepts to 
realize the complex human settlement system featured with harmonization.

\subsection{Focus on the development of small and medium- sized cities, effectively play the advantage of its}

2.2.1. Understand the connotation of the development, pay attention to the quality of urbanization

Urbanization is not only the physical expansion of cities and the growth of population, but also is a change of social production and life-style greatly. Urbanization should not only pay attention to the development of the economy, but also strengthen institutions and governance, including in key areas such as population administration, land management, finance and taxation, urban housing systems, public administration and environmental management. Urbanization can't strive merely for quantity of city, and should place greater emphasis on improving the quality of city to promote the development of long-term.

2.2.2. Optimize the industrial structure, promote the sustainable development

Throughout the history of world urbanization, each of great advances issued from industrial development. Urbanization must realize an industry to upgrade with transition, optimize and upgrade the industrial structure and balance the structures of primary, secondary and tertiary industries development.

To rely on technological innovation and scientific management, construct city's strategic industrial structure to promote the city sustainable development.

2.2.3 Regulate government management, perfect the management mechanism

China's urbanization is closely linked to the governmental system, the governments still runs key sectors of the economy directly and the rest indirectly. So, inevitably, the government plays an important part in the urbanization. Government should make scientific plans for the scale and layout of urban agglomerations; and make small and medium-sized cities better able to develop industries. To reach the goal of enhancing ability of management city, continuously promote overall reform in public utilities. We should separate government administration from the management of enterprises, state assets, public institutions, and social organizations, and build a well-structured, clean and efficient serviceoriented government.

\section{Conclusion}

Review the course of world urbanization, we can find the roads which each country taken are diversity and plenty. In Britain, urbanization was promoted by industrialization. Newtown construction is a key way for the urbanized advancement in South Korea. German vocational education pattern has played an important role in promoting urbanization. Although these successful experiences are well worth us to absorb and learn, these do not mean that we can accept hastily and without thinking it seriously. We should choose a right path of urbanization, which combined with China's conditions. For megacity, we should manage to control its size and continuously improve the quality of urban development, with a focus on improving the government administrative ability. For small and medium-sized city, we should transform the concept and model of development, stress the active function of people, handling properly the relationship between fairness and efficiency, with a focus on improving the quality of development. To improve the quality of urbanization, flexible, pertinent measures should be adopted in the light of different characteristics and steps of cities.

\section{Acknowledgment}

Supported by Langfang Science and Technology Bureau Grant No: 2014023079

\section{References}

[1]http://news.xinhuanet.com/politics/2013-02/

23/c_114772758.htm 